\title{
DESENVOLVIMENTO E INFLUÊNCIA DO MÉTODO MONTESSORIANO NO ENSINO
}

\author{
DESARROLLO Y INFLUENCIA DEL MÉTODO MONTESSORI EN LA ENSEÑANZA
}

DEVELOPMENT AND INFLUENCE OF THE MONTESSORI METHOD IN

TEACHING

\author{
Maria Inês Batista CAMPOS ${ }^{1}$ \\ Giovana Naime de Paula XAVIER ${ }^{2}$
}

RESUMO: Neste artigo, o objetivo é discutir a importância do método de observação para o desenvolvimento infantil de Maria Montessori no âmbito da educação. Partindo do eixo comparativo entre a biografia da médica e pedagoga e suas teorias em torno do desenvolvimento das crianças, buscou-se considerar seus experimentos na Casa dei Bambini. O foco é recuperar as inovações do método montessoriano, destacando a transformação do ensino da criança, respeitando suas fases evolutivas, o que tornou a sua teoria presente até os dias atuais, com a aprendizagem colaborativa e as escolas montessorianas ao redor do mundo. $\mathrm{O}$ resultado desta pesquisa mostra o cunho social das transformações feitas pela pesquisadora italiana, cuja vida foi consagrada a ensinar crianças deficientes e de baixa renda.

PALAVRAS-CHAVE: Lúdico. Teorias educacionais. Metodologia de ensino. Infância. Aprendizagem colaborativa.

RESUMEN: En este artículo, el objetivo es discutir la importancia del método de observación para el desarrollo infantil de Maria Montessori en el contexto de la educación. Partiendo del eje comparativo entre la biografía de la doctora y pedagoga y sus teorías en torno del desarrollo de los niños, buscamos considerar sus experimentos en la Casa dei Bambini. El enfoque es recuperar las innovaciones del método Montessori, destacando la transformación de la educación infantil, respetando sus fases evolutivas, que hizo presente su teoría hasta la actualidad, con el aprendizaje colaborativo y las escuelas Montessori de todo el mundo. El resultado de esta investigación muestra el carácter social de las transformaciones realizadas por la investigadora italiana, cuya vida estuvo dedicada a la enseñanza de niños discapacitados y de escasos recursos.

PALABRAS CLAVE: Lúdico. Teorías educativas. Metodología de enseñanza. Infancia. Aprendizaje colaborativo.

\footnotetext{
${ }^{1}$ Universidade de São Paulo (USP), São Paulo - SP - Brasil. Professora do Departamento de Letras Clássicas e Vernáculas (DLCV). Doutorado em Linguística Aplicada e Estudos da Linguagem (PUC-SP). ORCID: https://orcid.org/0000-0003-0004-9923. E-mail: maricamp@usp.br

${ }^{2}$ Universidade de São Paulo (USP), São Paulo - SP - Brasil. Graduanda do curso de Bacharelado e Licenciatura em Letras Português/Inglês, Departamento de Letras Clássicas e Vernáculas (DLCV). ORCID: https://orcid.org/0000-0002-8379-6002. E-mail: gionaime@usp.br
} 
ABSTRACT: This article has the objective of discussing the importance of Maria Montessori's observational method for children's development regarding education. A comparison between the doctor and educator's biography and her theories about development during childhood was made, taking into consideration her practical experiments, such as the Casa dei Bambini. The core of this study is summarized by the recovery of the innovations of the Montessori method, demonstrating its importance to the transformation of teaching, respecting children's evolutionary phases, all of which has kept her theory present even in present times, with collaborative learning and Montessori schools around the world. The results of this article show the social nature of the transformations made by the Italian researcher, whose life was dedicated to teaching special needs and low-income children.

KEYWORDS: Playful learning. Educational theories. Teaching methodology. Childhood. Collaborative learning.

\section{Introdução}

Neste artigo, o objetivo é apresentar o método pedagógico da italiana Maria Montessori (1870-1952) e seus princípios educacionais e filosóficos. Na Casa dei Bambini, escola criada por ela para acolher crianças abandonadas do bairro carente San Lorenzo, a pedagoga desenvolveu seu conceito de autonomia moral (também disciplina interior ou autodisciplina desenvolvida pela criança), a aprendizagem pelo uso de materiais didáticos de sua própria autoria, e seu próprio método de alfabetização. Em seguida, seus principais ideais pedagógicos e filosóficos acerca da infância e do ensino serão apresentados, como a possibilidade de transformação social por meio da escola, suas teorias sobre a percepção, a atividade independente e o espírito absorvente, assim como o ensino como um processo não linear. Além disso, ao abordar o início de sua trajetória pelo mundo da Educação por meio de sua atuação na clínica de psiquiatria de sua universidade, será possível considerar Montessori não somente em sua capacidade de pioneira do campo da Pedagogia, mas também como atuante área de Medicina. Segundo Ferrari (2008, s/p), “a evolução mental da criança acompanha o crescimento biológico e pode ser identificada em fases definidas, cada uma mais adequada a determinados tipos de conteúdo e aprendizado", o que atua como exemplo do embasamento biológico do método montessoriano.

A parte central desse artigo é a apresentação do método criado pela pedagoga e a importância das novas perspectivas trazidas por ela. Isso inclui suas críticas à pedagogia científica de sua época, a formação de professores centrada na observação dos alunos, a liberdade e autodisciplina do aluno, o aprendizado sensorial e suas propostas acerca da alfabetização e do ambiente escolar. Todas as inovações introduzidas por ela proporcionaram uma melhor compreensão da infância, assim como uma transformação do papel do professor e 
do aluno no aprendizado, conceitos cruciais para teorias como a aprendizagem colaborativa que temos na atualidade e para a manutenção de escolas montessorianas modernas.

\section{Um pouco da vida de Maria}

Em 31 de agosto de 1870, nasceu Maria Tecla Artemísia Montessori, em Chiaraville, uma comuna da província de Ancona, Itália. Seu pai, Alessandro Montessori, funcionário do Ministério das Finanças, e sua mãe, Renilde Stoppani, de família de classe média alta, culta, defendia ideais liberais. Sua família a criou com regras rigorosas, uma vez acreditavam no seu extraordinário potencial.

Aos cinco anos de idade, a pequena Maria mudou-se com a família para Roma porque seu pai fora transferido, e lá ela completou a educação básica e superior. Até a adolescência, a jovem pouco se interessava pelos estudos. Assim, ela entrou para a Escola Técnica focada em Matemática e Física (1886). Com a falta de recursos para contratar aulas particulares relacionadas ao currículo do Liceu Clássico, teve dificuldade em ingressar na Universidade de Roma. De 1890 a 1892, a jovem fez um curso preparatório em diversas disciplinas o que lhe permitiu ingressar no curso de Medicina (1893).

Dentro da universidade, Montessori enfrentou muito machismo. Ela fazia horas de dissecação e aulas de Anatomia separada de seus colegas, que eram todos homens. Contudo, com muito esforço e apoio de seus pais (especialmente de sua mãe), ela concluiu o curso de Medicina, sendo a primeira mulher italiana a fazê-lo.

Em 1897, a médica iniciou seu trabalho como assistente voluntária da clínica de psiquiatria da Universidade de Roma. Ela examinava crianças portadoras de deficiência intelectual que teriam condições de sair da clínica psiquiátrica e as submetia a atividades didáticas. Foi ao observar essas crianças que Montessori concluiu que elas ainda demonstravam vontade de brincar, e o que lhes faltava dentro da instituição psiquiátrica eram os estímulos adequados. Ao buscar formas para educá-las, ela encontrou os trabalhos de Bourneville, Itard, Séguin e Pereira, suas grandes inspirações (em especial, Itard e seu aluno, Séguin). Foi procurando proporcionar novas oportunidades para essas crianças consideradas menos capazes que ela decidiu estudar problemas educativos e pedagógicos. Em 1898, ela teve seu único filho, Mario, que foi criado longe dos pais no interior de Roma. Montessori só se reuniu com ele em 1912, após a morte de sua mãe.

Enquanto seguia essa linha de estudos, a educadora trabalhou de 1900 a 1902 na Scuola Magistrale Ortofrenica, um espaço de pesquisa e ensino dentro da Universidade de 
Roma de cuja fundação ela havia participado. Esse lugar funcionava tanto como uma escola modelo para crianças portadoras de deficiências diversas quanto como um espaço de formação para educadores, médicos, e outros especialistas com interesse nessa área. Buscando aprofundamento na área de Pedagogia, ela se inscreveu no curso de Filosofia da Universidade de Roma, a mesma universidade em que ela daria aula de Antropologia Pedagógica (1906).

Logo após sua formação em Pedagogia, Montessori recebeu um convite para revitalizar San Lorenzo, um bairro pobre de Roma. Foi lá que ela fundou a Casa dei Bambini, escola que acolhia e ensinava crianças que ficavam abandonadas pelas condições tão difíceis do bairro. Dessa forma, a pedagoga conseguiu, mais uma vez, dar uma educação de qualidade para crianças marginalizadas, promovendo um ensino sem restrições sociais. A partir das observações feitas pela educadora na Casa dei Bambini, ela foi criando uma configuração de sala de aula adequada para as crianças, dando a elas acesso a móveis e materiais adequados ao seu tamanho. Porém, depois de dois anos em São Lourenço e com a abertura de mais Casas dei Bambini, Montessori foi proibida de retornar ao bairro pelo desenvolvedor do projeto.

$\mathrm{Na}$ mesma época, ela publicou seu livro "O Método da Pedagogia Científica Aplicado à Educação Infantil nas Casas das Crianças", também conhecido como "O Método Montessori”. Ele foi escrito em uma fazenda emprestada por dois amigos, a qual se tornou o primeiro centro de formação de educadores montessorianos. Por causa do sucesso do livro, a Rainha Margarida da Itália financiou a primeira organização montessoriana.

Com a morte de sua mãe (1912), Montessori passou a viver com seu filho Mário, e abriu mão de seu cargo de pesquisadora da Universidade de Roma para propagar suas ideias sobre infância e educação. A pedagoga dirigiu o primeiro curso internacional para a formação de educadores em Roma em 1913. Com a excelente recepção, suas perspectivas se abriram nos Estados Unidos, onde Montessori publicou "Dr. Montessori's Own Handbook" (1914)". No ano seguinte, aceitou o convite da Exposição Internacional Panamá-Pacífico em São Francisco para criar uma sala montessoriana com paredes de vidro. Em 1919, viajou pela Europa disseminando seu método.

De volta à Itália, Benito Mussolini a recrutou para criar a Opera Montessori, órgão encarregado de disseminar seu método (1924). O governo italiano fundou a Regia Scuola di Metodo Montessori, voltada para a formação de professores em 1928, incluindo como modelo uma Casa dei Bambini. Nesta escola, o currículo, contudo, foi alterado pelo governo italiano, visando uma educação nacionalista. A educadora e seu filho criaram a Associação 
Montessori Internacional em 1929, e anos depois espalhou-se para outros países. Até hoje há essa associação em Amsterdã.

Com as incessantes modificações do governo italiano sobre seu trabalho, ela pediu demissão da Opera Montessori e da diretoria da Regia Scuola, pedindo que Mussolini retirasse o nome dela desses órgãos. Um ano depois, após ser vigiada incessantemente pelo governo italiano, Montessori se autoexilou na Catalunha, e em 1936, tanto a Opera Montessori quanto a Regia Scuola fecharam. Nesse mesmo ano começou a Guerra Civil Espanhola, que a levou a se mudar para a Inglaterra e, logo depois, para Laren, na Holanda. Foi lá que escreveu "Erdkinder", um livro voltado à educação do adolescente. Depois de três anos na Holanda, recebeu um convite para ir até a Índia, mas teve sua estadia estendida por 6 anos por causa de restrições de movimento causadas pela Segunda Guerra Mundial. Após ser libertada e retornar para a Holanda, ainda viajou, escreveu e estudou por muitos anos, falecendo somente aos quase 82 anos em 6 de maio 1952. (SALOMÃO, 2021) (RÖHRS, 2010).

\section{Centro de pesquisa}

As Casas dei Bambini foram o centro da pesquisa, da prática e do estabelecimento de teorias acerca da educação para Maria Montessori. Salomão alega que "[h]avia, de seu ponto de vista, a fabulosa conquista de se 'socializar a função materna', libertando a mulher para trabalhar, e a de 'redimir' a população mais pobre pela educação na Casa" (2021, s/p). A proposta desses estabelecimentos era serem inteiramente adaptados para as crianças, desde tamanho e peso da mobília até a estrutura do ambiente, com cores vibrantes, quadros, tapetes e materiais didáticos ao alcance delas. Esses procedimentos tinham a função de levar às crianças a viverem e transitarem por esses espaços a fim de criar um senso de responsabilidade e independência, o que lhes permitia também participar da manutenção dos espaços.

A partir do conceito de Rousseau de 'vontade geral', na qual a liberdade só é possível a partir do momento em que seguimos as leis que descobrimos e aplicamos, Montessori esperava que as crianças, ao transitarem pelos espaços das Casas dei Bambini e participarem do funcionamento da casa e de suas regras, desenvolvessem o conceito de autonomia moral, fazendo com que a disciplina viesse delas mesmas, e não do exterior. Dessa forma, ela desenvolveu um programa de exercícios de vida prática para que as crianças exercitassem a 
concentração, a paciência e a meditação, mas sempre aplicando esses conceitos a tarefas cotidianas.

A educadora desenvolveu materiais didáticos para ajudar no desenvolvimento das crianças. Eles eram criados e padronizados para que a criança pudesse escolher, de forma livre, se ocupar de certa atividade que ajudaria no desenvolvimento de seu intelecto. As crianças podiam, por exemplo, escolher exercícios de encaixar que contavam com cilindros de tamanhos e formatos diversos a serem inseridos em cavidades adaptadas. Assim, a criança aprenderia com seu próprio erro, pois a única solução é que, se o cilindro não encaixar, ela deve tentar novamente até que descubra qual seria a cavidade correspondente. Outra estratégia significativa é o desenvolvimento de materiais didáticos que permitiam às crianças avaliarem seu desempenho com facilidade. Se o professor pedisse que andasse em formato de círculo seguindo um desenho no chão, a criança identificaria rapidamente não ter conseguido seguir o caminho indicado, podendo corrigir a rota. Havia vários exercícios visando o estímulo de cada um dos sentidos, os quais eram praticados e discutidos em grupo. Isso desenvolvia as habilidades sociais da criança, vinculando sua vida social à educação. Contudo, o educador, por mais que pudesse disponibilizar e ensinar essas tarefas, não deveria interferir na liberdade das crianças, orientação dada por Montessori desde a primeira Casa dei Bambini. Ele somente deveria mostrar aquilo que é necessário e aquilo que é supérfluo, estabelecendo um limite.

Quanto ao método de alfabetização, ele foi desenvolvido na primeira Casa dei Bambini em San Lorenzo. A partir do momento em que as crianças pediram para serem ensinadas, Montessori criou as Letras de Lixa e o Alfabeto Móvel, o que lhes permitiu sentirem e replicarem os contornos das letras do alfabeto. Com isso, crianças pobres e abandonadas puderam alcançar o mesmo nível de alfabetização que as crianças em escolas tradicionais em tempo recorde (SALOMÃO, 2021).

\section{Princípios de sua visão sobre a educação}

Em primeiro lugar, Montessori acreditava que a infância é o elemento construtor da vida adulta, ou seja, o elemento mais importante. Por isso, ela aprovava das mudanças de visão que ocorriam na sociedade de sua época acerca da infância, as quais abriram espaço para que as necessidades da criança, diferentes das do adulto, fossem consideradas. Pensando nisso, ela escreveu a seguinte frase: "O problema social da infầncia nos faz penetrar nas leis 
da formação do homem e nos ajuda a criar uma nova consciência, levando-nos, consequentemente, a uma orientação da nossa vida social" (MONTESSORI, s/d, p. 11)

A partir desse pensamento, notamos que a médica considerava a educação um meio de transformação social. Ela sempre teve um olhar muito científico sobre a Pedagogia por causa de sua formação em Medicina. Seu método contava com fundamentos científicos, a começar pelo papel de observador do educador. Este deveria ficar à distância, observando em silêncio e só intervindo em momentos necessários. Além disso, após a observação detalhada e rigorosa, o educador deveria então interpretar os processos educativos. Contudo, Röhrs (2010) nota que, por mais que Montessori possuísse um método de observação muito objetivo e detalhado, suas interpretações eram muito mais subjetivas e careciam de rigor teórico e científico.

Montessori também criou sua própria teoria acerca da percepção. A respeito de seu material didático, ela decidiu que ele não devia tentar prender necessariamente a atenção da criança, permitindo a generalização e a abstração, mas não focando absolutamente nela. Ela afirmava também que a desvalorização da percepção direta é um erro, pois o que encontramos na natureza e à nossa volta pode ser ampliado de forma genérica e aplicado em situações estranhas a nós. A citação da pedagoga trazida por Röhrs ilustra esse conceito perfeitamente:

No seu conjunto, o mundo repete mais ou menos os mesmos elementos. Se estudarmos, por exemplo, a vida das plantas ou dos insetos na natureza, temos uma ideia aproximada da vida das plantas ou dos insetos no mundo inteiro. Ninguém conhece todas as plantas. Mas basta ver um pinheiro para conseguir imaginar como vivem todos os pinheiros (MONTESSORI apud RÖHRS, 2010, p. 26).

Nesse excerto, o autor nota que a observação da natureza com a extrapolação de conceitos a partir dela aproxima os pensamentos de Montessori das ideias de Pestalozzi, o qual dava muita ênfase à percepção direta e aprovava da exposição às tarefas cotidianas e à natureza.

Outro conceito de suma importância para seu método é o da atividade independente. Röhrs o explica a partir do conceito de liberdade: esta precisaria ser renunciada, e conforme a criança vai se desenvolvendo e adquirindo mais autonomia, a liberdade é reconquistada. Esse processo de reconquista é completamente consciente, contando com a criança reconhecendo seu valor e sua habilidade e amadurecendo a partir das atividades que realiza. Sendo assim, ao reconquistar sua liberdade, ela atinge a atividade independente, que teria como fim a autoeducação. 
Montessori considera também o conceito de espírito absorvente, que se relaciona intimamente ao desenvolvimento infantil. As crianças, por mais que sejam desde o início dotadas de inteligência, têm o aspecto físico como predominante. Por isso, sua educação deve ser equilibrada entre estímulos físicos e psíquicos durante seu estágio de desenvolvimento primário. Se ela focar somente nos estímulos físicos, as crianças, por serem espíritos absorventes, podem internalizar impressões e experiências que observam ao seu redor que solidificam conceitos errados ou inadequados para seu desenvolvimento, já que esse comportamento absorvente não possui filtro. O espírito absorvente é, então, a capacidade e a vontade de aprender, as quais se direcionam para o meio externo para extraírem experiências e conhecimento. Ou seja, como disse Montessori, "na criança existe a atitude criativa, a energia potencial, para construir um mundo psíquico às expensas do ambiente" (s/d, p. 50). Desse modo, como o meio externo tem uma importância tão grande nesse processo, a organização do meio em que a criança aprende é crucial. Röhrs seleciona o seguinte pensamento da autora para expressar essa ideia:

O primeiro passo da educação é prover a criança de um meio que the desenvolver as funções que lhes foram designadas pela natureza. Isso não significa que devemos contentá-la e deixá-la fazer tudo o que lhe agrada, mas nos dispor a colaborar com a ordem da natureza, com uma de suas leis, que quer que esse desenvolvimento se efetue por experiências próprias da criança (MONTESSORI apud RÖHRS, 2010, p. 29).

De acordo com ela, não somente o meio deve ser monitorado para que ele possa desenvolver as funções adequadas da criança, mas isso deve ser feito de modo que a natureza não seja desrespeitada, contando com a atividade independente da criança.

Uma noção central refere-se ao entendimento de Montessori sobre a educação, que considera o aprendizado como um processo não-linear. Na verdade, o aprendizado seria constituído por uma sequência de "explosões", também descritas como "despertares" ou "revelações", que movem a evolução do indivíduo (MONTESSORI, s/d, p. 31). Além disso, essas explosões não podem ser previstas de forma alguma.

\section{A proposta de método de Montessori}

A pedagogia na época em que a autora iniciou seus estudos acerca da educação, intitulada 'pedagogia científica', contava com uma formação médica, com 'educadores científicos’ que utilizavam medições físicas e antropológicas de crianças para seu ensino. Assim, era difícil formar educadores a partir da iniciação em experimentação, fazendo com 
que Montessori propusesse o seguinte: uma formação de professores pela observação ao mesmo tempo que a escola sofresse uma grande transformação. Nessa nova proposta de escola, as crianças devem poder ser espontâneas e ter liberdade para desenvolverem suas personalidades. É somente dessa forma que os educadores em formação poderão observá-las e criar um estudo individual de cada educando. A pedagoga também elabora sobre o conceito de liberdade das crianças sobre a qual ela tanto discorre: a liberdade não é qualquer atividade desordenada que a criança faria se abandonassem-na, mas sim a libertação de qualquer coisa que a impeça de seguir seu desenvolvimento natural.

Em relação à sua proposta de método, aplicada inicialmente nas crianças com necessidades especiais e depois no resto das crianças com quem trabalhou, Montessori desenvolveu primeiramente a ideia de que somente mensurações não eram o suficiente para educar, assim como muitos de sua época imaginavam, mas que a educação deveria modificar algo na criança, tendo resultados mais impactantes e permanentes. $\mathrm{O}$ seguinte pensamento de Montessori resume de forma concisa aquilo que ela acreditava sobre a pedagogia científica:

Enquanto os investigadores se limitassem a ventilar 'novos problemas', não haveria fundamento para afirmar que estava surgindo uma 'pedagogia científica': é a solução dos problemas que ela deve aportar, e não só a evidência das dificuldades e dos perigos, tanto tempo ignorados dos responsáveis pela educação das crianças (MONTESSORI, 1965, p. 41).

Ela também explicou o porquê de o estudo da psicologia infantil não ser produtivo ao observar a criança em um ambiente escolar tradicional: as crianças ficariam defensivas ou cansadas no ambiente escolar, que apresenta características que fogem à vida diária da criança. Dessa maneira, as crianças não demonstrariam seus verdadeiros impulsos e personalidades na escola, dificultando a descoberta de suas leis psicológicas e de seu caráter natural. Isso explica a necessidade que a educadora tanto sentia de transformar a escola em um espaço cuja função era acomodar a criança para que ela exercesse suas vontades e pudesse se desenvolver livremente.

Quando se trata de disciplina, Montessori nunca aplicava punições, alegando que elas são necessárias somente para delinquentes e para pessoas inferiores. O que ela considerava como um indivíduo disciplinado também não é aquele que fica quieto e imóvel o tempo todo, e sim um indivíduo ativo, dono de si e que sabe transitar entre as regras da vida. Essa disciplina deve ser aplicada não somente ao ambiente escolar, mas para o resto de sua vida social, tendo como guia o interesse coletivo: a criança deve aprender a limitar sua liberdade para que suas ações não machuquem, prejudiquem ou ofendam os outros. Para que isso seja 
possível, a noção de bem e mal deve ser internalizada pela criança, sem que o mal tenha associação com a atividade e o bem como a imobilidade, como acontece no ensino tradicional. Assim, o educador deve disciplinar a atividade, se assegurando de que ela seja, nas palavras de Montessori, "útil, inteligente e consciente, sem manifestar nenhuma indelicadeza" (MONTESSORI, 1965, p. 50). Por último, ela também afirma que o desenvolvimento psíquico é necessário para que haja disciplina, pois a criança não pode obedecer sem que ela saiba o que é obedecer, ou porque está obedecendo.

Em relação ao físico da criança, a autora afirma que ela está sempre se movimentando ou sentindo necessidade de movimento. Por isso é que se deve realizar uma educação muscular da criança: conforme ela vai desenvolvendo melhor seu movimento, ela será capaz de controlá-lo e inibi-lo quando julgar necessário.

Ela também considerava importante o desenvolvimento dos sentidos, em especial para a primeira infância. Esse desenvolvimento se enquadra dentro da educação geral, que tem por função preparar o indivíduo para seu ambiente, vindo antes de operações intelectuais mais avançadas. Para isso, deve-se introduzir às crianças diversos estímulos de forma gradativa, mostrando como diferenciar cada um e como distinguir pequenas quantidades de certo estímulo, afinando, assim, os sentidos. Montessori adianta que essas habilidades são necessárias para a educação moral e para a educação estética. Ademais, o tato é especialmente importante e deve ser adequadamente desenvolvido, pois dependemos dele para boa quantidade de nossas atividades diárias. O tato é, também, imprescindível para o método de alfabetização montessoriano. Um outro sentido ao qual ela atribui enorme importância é a audição, pois é a partir dela que um indivíduo percebe movimentos a partir dos sons. A audição também permite a noção de silêncio, o qual a pedagoga entrelaça com seu conceito de disciplina:

[O] silêncio deve ser entendido de um modo positivo, como um "estado superior" à ordem normal das coisas, como uma inibição instantânea que exige um esforço, uma tensão da vontade, que elimina os ruídos da vida cotidiana, como que isolando a alma das vozes exteriores (MONTESSORI, 1965, p. 138).

Atingir o completo silêncio contaria, então, não somente com uma percepção auditiva bem desenvolvida, mas também com um senso de autocontrole e de consciência de si. Outra ideia importante para seu método é a de lições. As lições seriam os momentos nos quais o educador apresenta um novo objeto para as crianças, explicitando suas funções e como usá-lo por meio de palavras ou demonstrações. Essas lições devem ser objetivas e expressas da 
forma mais concisa e verdadeira possível. Caso a criança não demonstre interesse no objeto, a lição não deve ser repetida e o educador não pode indicar para a criança que ela não compreendeu a lição. Algo importantíssimo a explicitar é o fato de que as lições não são um simples auxílio para o educador ensinar, mas elas próprias são o meio didático pelo qual as crianças aprendem. Dessa forma, se a criança descobrir um interesse pela atividade apresentada na lição, ao executar a tarefa, o objeto se torna um "meio de desenvolvimento" (MONTESSORI, 1965, p. 143).

Em se tratando da alfabetização, Montessori considera que ela depende do pensamento logicamente organizado e de uma capacidade de retomar pessoas e objetos ausentes. Esse é um estágio avançado de desenvolvimento, e se a criança não tiver essas habilidades consolidadas, é muito cedo para ensinar a linguagem escrita para a criança. Ainda com relação à alfabetização, a educadora diz que leitura e escrita não são processos aprendidos simultaneamente:

[A] escrita, conquanto esta asserção contradiga certo preconceito, precede a leitura. [...] Denomino leitura a interpretação de uma ideia latente em sinais gráficos (MONTESSORI, 1965, p. 214).

Tendo isso em mente, primeiro deve-se tentar ensinar a formação das palavras a partir de letras móveis para depois reconhecer significados e interpretar ideias a partir delas.

\section{Escola Nova}

As Casas dei Bambini e toda a proposta de reforma educacional por trás delas fizeram com que Montessori se tornasse uma das grandes figuras do movimento internacional da Escola Nova. Porém, ela apresentava diferenças grandes em relação a outros participantes desse movimento. A pesquisadora sempre atestou ter sido fortemente influenciada por Rousseau, em especial por seu tratado sobre a educação intitulado 'Emile'. Assim, ela tomou para si as ideias de que o mundo dos adultos não leva em conta as crianças e de que se deve respeitar a natureza das crianças, deixando-as se desenvolver livremente. Além disso, ela nunca colaborou diretamente com outros nomes da Escola Nova, sendo somente indiretamente influenciada por alguns deles, a saber, Percy Nunn e Ovide Decroly.

No caso de Percy Nunn, Montessori o conheceu enquanto ele dava um ciclo de palestras em Londres. Foi lá que ela descobriu suas teorias do hôrmico - ou força vital, que faz com que o indivíduo busque a realização de si mesmo - e da memória, as quais a inspiraram para criar o seu conceito do espírito humano em desenvolvimento. De acordo 
com essa teoria, o espírito humano só adquire sua forma ao interagir com o ambiente exterior, sendo moldado por ele. Já no caso de Ovide Decroly, a inspiração vai mais a fundo, especialmente por suas trajetórias e histórias de vida serem tão similares. Os dois tinham um ano de diferença de idade, eram formados em Medicina e, portanto, tinham uma visão da educação e da criança mais voltada à ciência e à Biologia. Eles também criaram estabelecimentos de ensino próprios no mesmo ano (1907) e estudaram Itard e Séguin como base para suas práticas educacionais (RÖHRS, 2010).

\section{Aprendizagem colaborativa}

A aprendizagem colaborativa, um recurso educativo, é resumida da seguinte maneira por Torres e Irala: "Em um contexto escolar, a aprendizagem colaborativa seria duas ou mais pessoas trabalhando em grupos com objetivos compartilhados, auxiliando-se mutuamente na construção de conhecimento" (2014, p. 65). O papel do professor, nesse caso, seria o de criar situações de aprendizagem para que ocorram trocas propícias entre os alunos e entre cada aluno e o próprio professor.

Essa técnica integra várias tendências pedagógicas e bases teóricas, com uma delas sendo a própria Escola Nova, movimento do qual Montessori fazia parte. John Dewey, Freinet, Ferrière, além da própria Montessori, foram alguns dos integrantes da Escola Nova que propuseram uma educação com o aluno no centro, focando em seu autodesenvolvimento e tendo suas experiências e necessidades como prioridade. A centralidade do aluno no processo educacional permite que ele leve seus conhecimentos para o mundo, organizando sua própria realidade e integrando-se ao seu meio. Torres e Irala completam esse pensamento, dizendo que "essa nova abordagem, de contorno humanista, enfatizava o sujeito como principal elaborador do conhecimento humano e priorizava as relações interpessoais para o desenvolvimento humano" (2014, p. 70). Essa ideia pode ser vista no conceito de liberdade de Montessori, que deixa o aluno livre para escolher suas atividades e para enfrentar as dificuldades que ele encontra de formas variadas, inclusive comunicando os problemas encontrados com seus colegas ou com seu professor.

O aluno como eixo central da aprendizagem tem, como já foi observado durante a descrição do método montessoriano, a consequência de tirar o protagonismo do professor como transmissor de conhecimento e detentor da verdade. Isso traz consigo um novo papel para o professor: o de facilitador. Esse fato se dá não somente com a teoria de Montessori, mas na Escola nova e na aprendizagem colaborativa como um todo. $\mathrm{O}$ professor tem como 
objetivo proporcionar atividades e condições no ambiente escolar que promovam o desenvolvimento individual de cada aluno, seja por interação com os colegas, com o professor ou com o próprio ambiente.

Torres e Irala trazem um pensamento de Panitz que esclarece ainda mais o processo de aprendizagem colaborativa: ele a caracteriza como "uma maneira de lidar com as pessoas que respeita e destaca as habilidades e contribuições individuais de cada membro do grupo." (PANITZ apud TORRES; IRALA, 2014, p. 67). O aluno, ao ser colocado em uma situação que exige colaboração com o outro, tem sua parcela de responsabilidade sobre o processo de colaboração e de autoridade de pensamento e de ação, assim como os outros alunos. Isso preserva sua centralidade no processo de aprendizado, pois ele tem de monitorar e dirigir suas ações, e ainda o apresenta a novas formas de pensar e agir vindas de outros indivíduos. Dessa forma, o aluno aprende a interagir em uma variedade de contextos, sejam eles sociais, culturais, históricos ou políticos.

Por mais que o método de Montessori pressuponha a colaboração, Ferrari afirma que “[.... [a]s críticas mais comuns ao montessorianismo referem-se ao enfoque individualista" (FERRARI, 2008, s/p). Isso demonstra que há uma má compreensão ou aplicação do método, pois Montessori sempre pregou um ambiente escolar voltado para o uso coletivo, materiais didáticos a serem compartilhados e um enfoque do aprendizado individual que tem como fim a atuação no mundo e em sociedade.

\section{O ensino montessoriano na atualidade}

É possível encontrar, atualmente, escolas estritamente montessorianas ao redor do mundo. Talita de Almeida, presidente fundadora da Associação Brasileira de Educação Montessoriana (ABEM), afirma que "os grandes centros de educação se encontram no México, Japão, Estados Unidos e Índia” (1984, p. 10). Outrossim, por mais que o método inicial da educadora tenha sido testado em crianças de três a seis anos, a professora da Faculdade de Educação da Universidade de São Paulo (USP), Carlota Boto, afirma que "o desenvolvimento do ser humano começa logo quando ele nasce e vai até os 24 anos", e por isso, "enquanto filosofia, é possível pensar o método [Montessori] também nas fases subsequentes [às primeiras etapas da vida]" (BOTO apud DISERÓ, 2018, s/p). Sendo assim, justifica-se que na segunda década do século XXI, o método Montessori dirige-se a grávidas e há também uma tentativa de ensino universitário na Índia. 
No Brasil, no entanto, há muitas escolas fundamentadas no método Montessori, que chegou no país nos anos 1960, nas cidades de São Paulo e Rio de Janeiro. Entretanto, ele não obteve grande disseminação, tanto entre os educadores quanto entre o público geral. Almeida atribui esse desconhecimento aos seguintes fatores: à falta de profissionais devidamente formados no método, poucas certificações dos Centros e Cursos Internacionais Montessori; à formação de muitos ditos montessorianos ser feita somente com acesso às sete obras de Montessori traduzidas para o Português; e à comercialização do método, cuja popularidade ao redor do mundo faz com que ele seja usado como rótulo para atrair novos matriculados (ALMEIDA, 1984).

Em se tratando da manutenção dos valores instituídos pela pedagoga, observa-se que o método Montessori ainda funciona como um método não elitizado, que preza por atender a todos. Suas escolas acolhem todas as crianças, independente de classe social, e "seus melhores resultados são com crianças carentes, de classe $\mathrm{C}$, que precisam dos estímulos que todo o instrumental oferece" (1984, p. 17), completa Almeida. Ela ainda adiciona que, assim como as primeiras escolas criadas por Montessori se encontravam em bairros carentes, como San Lorenzo, muitas escolas na Europa, nos Estados Unidos e no México são criadas e mantidas pelo governo ou por grupos de pais operários, o que parece indicar que a ideia inicial de acessibilidade da educadora continua viva.

\section{Considerações finais}

Maria Montessori, a partir das experiências cotidianas, compreendeu a importância de estimular a criança e de aprimorar o ensino de modo a atendê-la em todas as necessidades educacionais, assim consolidou essa busca, particularmente, no seu período de trabalho na clínica de psiquiatria da Universidade de Roma. Uma vida inteira dedicada a proporcionar às crianças portadoras de deficiência e às crianças de bairros carentes uma experiência de aprendizado de qualidade. Tal legado é visto até hoje como inovador, e as escolas montessorianas procuram atender populações proletárias ou de baixa renda ${ }^{3}$.

Seguindo esse rumo dedicado ao bem das crianças, a médica contribuiu com muitas inovações para a pedagogia e para a educação. Seu novo modelo de sala de aula, sua nova proposta de formação para os educadores pautada na observação, sua forma tão criativa de

${ }^{3} \mathrm{O}$ Brasil conta com mais de 60 escolas montessorianas filiadas à Organização Montessori do Brasil (OMB), como a Aguai Escola Montessoriana na cidade de São Paulo (São Paulo), a Aldeia Núcleo de Educação Montessori na cidade do Rio de Janeiro (Rio de Janeiro), e a Escola Maria Montessori na cidade de Cruz das Almas (Bahia). (CONFIRA, s/d) 
alfabetização e seu entendimento da criança baseado na liberdade e no autoconhecimento são algumas das propostas que entendem a criança carente como um ser humano que merece todo apoio e formação. Nessa concepção de criança, seu método de ensino é até hoje influente no mundo da educação, pois se identifica com a aprendizagem colaborativa e persiste com a manutenção de escolas dedicadas à sua metodologia.

No que diz respeito ao ensino atual, contemplando todas as idades, as maiores contribuições de Montessori são, com certeza, seus princípios de autonomia moral e o da liberdade do aluno. A aquisição da autodisciplina e da noção de responsabilidade que advêm do princípio de autonomia moral formam um indivíduo muito mais preparado para viver em sociedade e para adquirir conhecimento em qualquer área de ensino. Por outro lado, a liberdade do aluno de escolher o assunto de seu estudo e o passo em que ele vai desenvolver seu conhecimento proporciona um autoconhecimento necessário para que o indivíduo atinja seu potencial máximo e saiba respeitar seus limites. Isso possibilita um conhecimento para além de situações acadêmicas, um elemento essencial e escasso na educação formal que seria benéfico a ela.

Para a aplicação desses ideais em disciplinas específicas, em especial fora das etapas iniciais de desenvolvimento da criança, talvez seja mais provável e proveitosa uma aplicação filosófica, menos presa a uma metodologia estritamente montessoriana. Considerando o uso dos princípios de colaboração e de liberdade no ensino da Língua Portuguesa, por exemplo, é possível que os indivíduos que entrem em contato com essa área não encarem o aprendizado da gramática de uma forma tão normativa por estarem colaborando com colegas e professores com uma bagagem linguística diferente em um ambiente que estimula a pluralidade, assim como proposto por Montessori. Isso facilitaria o ensino de variação linguística, o qual não é muito prevalente em escolas brasileiras. Além disso, a liberdade de escolha dos assuntos sobre os quais o aluno prefere aprender retira a expectativa de um aprendizado compulsório e truncado de estruturas gramaticais. Isso permite que o aluno busque aprender sobre a língua usando estratégias mais adequadas à sua forma de conhecer o mundo, fugindo ao ensino tradicional e descobrindo um gosto pelo funcionamento da língua que ele não teria descoberto no ensino tradicional. Essa adaptabilidade é o que torna os princípios e o método de Montessori tão acessíveis e, consequentemente, tão igualitários. 


\section{REFERÊNCIAS}

ALMEIDA, T. D. Montessori: O tempo o faz cada vez mais atual. Perspectiva, v. 1, n. 2, p. 9-19, 1984.

DISERÓ, B. Método montessoriano tem alta no número de adeptos no Brasil. Agência Universitária de Notícias (AUN) - USP, São Paulo, 04 jul. 2018. Disponível em: http://aun.webhostusp.sti.usp.br/index.php/2018/07/04/metodo-montessoriano-tem-alta-nonumero-de-adeptos-no-brasil/. Acesso em: 08 set. 2021.

FERRARI, M. Maria Montessori, a médica que valorizou o aluno. Nova Escola, 01 out. 2008. Disponível em: https://novaescola.org.br/conteudo/459/medica-valorizou-aluno\#. Acesso em: 10 ago. 2021. 4.

MELHOR ESCOLA. Confira a lista das escolas Montessori no Brasil. São Paulo, s.d. Disponível em: https://www.melhorescola.com.br/artigos/confira-a-lista-das-escolasmontessori-no-brasil. Acesso em: 08 set. 2021.

MONTESSORI, M. Pedagogia científica: a descoberta da criança. Trad. Aury Azelio Brunetti. São Paulo: Flamboyant, 1965.

MONTESSORI, M. A criança. Trad. Luiz Horácio da Matta. 2. ed. Rio de Janeiro: Nórdica, s/d.

RÖHRS, H. Maria Montessori. Trad. Danilo Di Manno de Almeida, Maria Leila Alves. Recife: Massangana, 2010.

SALOMÃO, G. Maria Montessori: Biografia. Lar Montessori, 2021. Disponível em: https://larmontessori.com/maria-montessori-biografia-2/. Acesso em: 08 jun. 2021.

TORRES, P. L.; IRALA, E. A. Aprendizagem Colaborativa: Teoria e Prática. Programa Agrinho, Paraná, 2014. Disponível em: https://www.agrinho.com.br/site/wpcontent/uploads/2014/09/2_03_Aprendizagem-colaborativa.pdf. Acesso em: 10 ago. 2021.

\section{Como referenciar este artigo}

CAMPOS, M. I. B.; XAVIER, G. N. P. Desenvolvimento e influência do método montessoriano no ensino. Rev. Sem Aspas, Araraquara, v. 10, n. 00, e021017, jan./dez. 2021. e-ISSN: 2358-4238. DOI: https://doi.org/10.29373/sas.v10i00.15803

Submetido em: 07/09/2021

Revisões requeridas: $12 / 10 / 2021$

Aprovado em: $15 / 11 / 2021$

Publicado em: 29/12/2021 